\title{
Care in the Silver Years: Academics Perception of Institutional Care for the Elderly in Ghana
}

\section{Esmeranda Manful}

Lecturer, Department of Sociology and Social Work; emanful.cass@knust.edu.gh

Edward Asamoah

Assistant Lecturer, Department of Sociology and Social Work; eddylinc@yahoo.com

\section{Anthony Boateng Bediako}

Teaching Assistant, Department of Sociology and Social Work; anthonyboatengbediako@gmail.com

\section{Doi:10.5901/mjss.2015.v6n6s4p220}

\section{Abstract}

Population trends are indicative that by $2050,10 \%$ of Ghana's population will be above 60 years. Yet, only a minority live with a relative that might provide care and support for them. This suggests that there is a need for an alternative care option for the majority who might need care and support but will have no relative capable or available to provide such care, probably the solution will be institutional care that will provide the needed care services. However, there is a gap in the literature as to how Ghanaians might accept such an option. Using a qualitative research design, this study aimed at exploring the views of academics on institutional care as an alternative care option for Ghanaians. The findings revealed that majority of the academics shared the merits of having such an institution but the major concern was adequate care and how it will be managed. It was concluded that in other to demystify the concept of institutional care, day care centres for the elderly should be introduced, training of more personnel in gerontology for them to have the requisite skills to attend to the elderly and the encouragement of private-public partnership to ensure efficient and effective provision of care services for the elderly.

Keywords: Elderly, Ghana, Institutional Care, Academics, Social Policy.

\section{Introduction}

The care for the elderly, like all other care issues, is considered as best addressed in the private sphere; specifically within the family. Unlike child care issues where State or non-family intervention has been accepted and is in public discourses, the care for the elderly is often deemed as a private issue that is best addressed within the family and in the community without interference from the State or other individuals (UN, 2002). Yet population trends are changing, even Africa which global estimates indicate that it is the youngest region with $6 \%$ of its population being over 60 years compared with $22 \%$ in Europe (Pillay \& Maharaj, 2013), will by 2050, have around 10\% of its population above 60 years (Ghana Statistical Service, 2012; World Population Ageing, 2011). Thus, with the increase in the numbers of the elderly coupled with the disintegration of the extended family system; an alternative care option for the elderly is a discourse that needs apt attention in the social policy domain.

African families have always catered for their elderly in their old age. Caring for a person in general was not the sole responsibility of the family but that of the community as a whole (Nukunya, 2003). Provision of basic needs like food and shelter was never an issue in traditional communities for the elderly. However, there is a gradual breakup of the traditional large extended family system which has led to gaps in the care of older family members. Several factors including urbanisation and modernisation have led to the breakdown of traditional societies in Africa with the 'we' concept of the African dying gradually (Nukunya, 2003). Therefore this change in the social structure, which has affected the family, requires a different approach to health and social sector policy for the elderly (World Health Organisation, 2008). More importantly, addressing the care needs of the elderly across the African continent will require changes in the provision of care. For example South Africa and Botswana have formalised institutions providing care for their elderly (Tibutt, 1983); as the traditional system cannot be relied on to provide care for everyone.

In Ghana, the 2010 Population and Housing Census Report revealed that only 8.3\% of the elderly may receive 
care and support from a relative they live with (Ghana Statistical Service, 2013). This suggests that a large proportion will need care; hence there is a need for an alternative care option, probably institutional care that will provide the needed care services. Thus, institutional care for the elderly has to be considered in the social policy domain. Yet, there is a gap in the literature on how such a concept of non-family care provision might be accepted by the Ghanaian society. This paper presents findings from a qualitative study which sought to explore the views of academics, one of the many stakeholders relevant to the policy development, on the concept of providing elderly Ghanaians with institutional care services. The objectives of the study were to explore the understanding of the concept of institutional care of the elderly, whether it is a care option they might opt for their elderly relatives and how such a service should be managed.

\subsection{Conceptualisation of Care for the Elderly}

Being referred to as 'elderly' is a social construction that differs from time periods and societies. Also, the term elderly can be defined using biological, historical and cultural concepts; however this results in varied definitions and dimensions (Atchley \& Barusch, 2004). For instance, in relation to social policy the preferred definition of the elderly is often tied to eligibility for State pensions. Thus in social policy, the elderly is defined using the biological concept, referring to a group of individuals who have attained a certain age, linked with economic activity in the public sector. This has resulted in varied age reference to the elderly. In developed countries where life expectancy is high and the age of retirement from public institutions is pegged at age 65; the elderly are referred to as individuals who are 65 years and above. On the other hand, in developing countries where life expectancy is comparatively lower and the age of retirement from public institutions is largely pegged at age 60, the elderly are referred to as individuals who are above 60 years (United Nations Population Fund and HelpAge, 2012). These definitions reveal the contextual differences between developed countries and developing countries, in relation to State pension benefits. Also, the definition is likely to exclude the majority of individuals, in both developed and developing countries, who do not benefit from State pensions. These notwithstanding, to present a more homogeneous definition in the discourse on the elderly, the United Nations refer to the elderly as any individual who is above 60 years (United Nations Population Fund and HelpAge, 2012).

Caring for the elderly has always been part of human relations on the basis that elderly people would be taken in by family members once they were unable to care for themselves (Little, 2013). However, in the nineteen century nonfamily intervention in the care for the elderly began in Europe and North America. There were two main differences though, it was observed that those who had no family could rely on servants if they had the financial resources, but for those who were alone and poor the only choice was the local almshouse (Stevenson, 1994). Also, in the United States, women's and church groups began to establish special homes for the elderly persons, for instance, Philadelphia's Indigent Widows' and Single Women's Society were some of the earliest groups to establish care homes for the elderly in 1823 (Haber, 1977).

Thus, in instances where the family or community fails to provide care for the elderly who are frail and or in ill health; institutional care is the best alternative (UN, 2002). Institutional care has several challenges; the prominent ones are lack of autonomy and elderly abuse. Studies suggest lack of autonomy as one of the main concerns of residents living in nursing homes (Andresen \& Puggaard, 2008; Scott et al., 2003). Autonomy may be described as an agreement to respect another's right to self-determine a course of action; support of independent decision making (Beauchamp \& Childress, 2009). A study by Murphy et al. (2006) also found out that many problems experienced on daily basis by the elderly in long-term care has to do with the notion of autonomy, based on individual's own choices in decisions and activities. Secondly, elderly abuse is one of the challenges identified in institutions caring for the elderly. Elderly abuse is defined as a 'single or repeated act or lack of an appropriate action, occurring within any relationship where there is an expectation of trust and which causes harm or distress to an older person' (World Health Organisation, 2006:1).

\subsection{Characteristics of the elderly in Ghana}

The 2010 Population and Housing Census revealed a changing demographics and socio-economic characteristics of the elderly in Ghana (Ghana Statistical Service, 2013). The census revealed that, the population of the elderly have increased seven folds in the last five decades, from 213,477 in 1960 to $1,643,381$ in 2010 . Also, 54\% of the elderly reside in the rural areas and more than $90 \%$ are affiliated to a religion. The report further showed a higher proportion of life expectancy for female, $56 \%$ as compared to the proportion of males $44 \%$. Further, approximately three out of every four males were married as compared to one in three females at the time of the census.

The report also revealed that $58.5 \%$ of the elderly were economically active, with majority of them in the agricultural sector and self-employed, and a minority in skilled professions. The large proportion in unskilled profession 
was attributed to the low educational level of the elderly with $60 \%$ having had no formal education and $1.5 \%$ had attained tertiary level of education. Further, the census report highlighted the fact that a high proportion of the elderly live in homes with limited access to sanitation facilities and other social amenities; for example $34 \%$ had to use public toilet facilities and $22 \%$ had no access to a toilet facility. In addition, their living arrangements suggest that, only $8.3 \%$ of them may receive care and support from a relative who they live with; whilst the proportion of those who live alone was $9 \%$ for the 60 - 69 years and $11.4 \%$ for the $75-79$ years.

\section{Research Design}

This study employed the qualitative approach which is about exploring issues, understanding phenomena and answering questions by analysing and making sense of unstructured data (Berg, 2001). This approach was adopted instead of the quantitative approach as the main goal was to explore the perception and not the quantification of the views on elderly care. The study was conducted in Kwame Nkrumah University of Science and Technology (KNUST), one of the eight public universities in Ghana. The university operates the Collegiate system with six colleges, namely; College of Engineering, College of Science, College of Art and Built Environment, College of Agriculture and Natural Resources, College of Health Sciences and the College of Humanities and Social Sciences. This study focused on members of faculty as its main objective was to explore their perception of institutional care for the elderly.

The research method employed for the study was in-depth interview. In-depth interviews were the most appropriate method for the study since the research sought to explore the perception and opinions of the members of faculty to produce authentic data (Marvasti, 2004). There was the need therefore to allow participants to express themselves freely so that their opinions on institutional care for the elderly could be collated.

Further, any member of faculty who had worked for at least one year within the university was eligible to participate in the research. Hence, initial visits were paid randomly to academics in the various colleges, who met the criteria, to invite them to participate in the study. Appointments were booked with the academics who agreed to participate in the study and dates were set for the interviews. There are varied opinions on how many interviews are adequate in qualitative studies. Guest et al. (2006) argue that they achieved data saturation after analysing 12 out of 60 interviews whereas Creswell (2013) in contrast argues that to reach data saturation you must have conducted between 20 and 60 interviews. This is indicative that there is no magic number that constitutes sufficient data in qualitative studies (Bruce, 2007). Therefore this study adopted Francis et al. (2010) proposed ' $10+3$ ' formula; where for at least every 10 interviews, three more are conducted to ascertain if new insights are being gained. In this study, data saturation was reached after the first 10 interviews, but the study continued to double the number of participants in the quest of the possibility of new insights. This was to ensure it met at least the minimum criteria for data saturation as suggested by major qualitative researchers. Hence, over a period of one month, 26 senior members volunteered to participate in the study, with at least four participants from each faculty with the exception of College of Engineering where only one senior member participated.

The interviews took place in the offices of the research participants. Majority of the in-depth interviews were audio recorded but there were some research participants who preferred their responses to be written down. In all, 17 research participants' responses were recorded whilst the remaining nine responses were recorded in a note book during the interview session. The audio recorded interviews were transcribed and all the interviews were converted into 'MS-Word' format. Qualitative analysis software, NVivo was used to manage and aid in the thematic analysis of the data obtained. Using the NVivo software, the transcribed data was imported from 'MS-Word' as nodes. Each research objective was created as a node and the corresponding responses were coded into it; after identifying reoccurring themes these were created as sub-nodes and the entire interview data coded accordingly.

\section{Findings and Discussions}

\subsection{Understanding of Institutional Care for the Elderly}

One of the objectives of the study was to explore research participants' knowledge about institutional care for the elderly. All research participants interviewed knew about Institutional Care for the Elderly. Some had first-hand knowledge from working in such institutions outside Ghana during their studies whilst others expressed knowledge about Institutional Care for the Elderly from watching movies and hearing of it on the news and other documents. But as to what Institutional Care for the Elderly actually entails, two themes emerged from the interview data. These are Institutional Care for Elderly being a residential facility where the elderly are sent to and a non-family care service where the care needs of the elderly are 
addressed by paid personnel in their respective homes.

\subsubsection{Residential Facility}

Some research participants explained Institutional Care for the Elderly as a residential facility where the elderly are sent by their family members when they become old and unable to care for themselves. They further stated that it could also be the case that the elderly might have no one to care for them and as a result could also be sent to such a facility. One research participant had this to say;

"Well if people are unable to care for their parents or grandparents they take them to such institutions which have been set up for such purposes, to be taken care of by other people, nurses and other professionals. Depending on how the institution is set up, activities are sometimes organised for the residents. There are also instances where homeless people are taken in by such institutions." (P13)

The understanding of what institutional care for the elderly entails is in line with the description of Nursing Homes as 'institutional facilities licensed by the state that offer 24-hour room and board, supervision and nursing care' (Wysocki et al., 2012:2).

\subsubsection{Non-family paid services}

On the other hand, other research participants described Institutional Care for the Elderly as a paid service provided by private organisations or even public institutions that train nurses or care attendants to attend to the elderly in their homes. They further explained that the nurses cater for the health needs of the elderly in most cases and serve as 'babysitters' to the elderly adding however that such services are costly and only few people can afford such services. This is what one research participant had to say;

\section{"Institutional care for the aged is a lucrative business. You can hire people to come and take care of your elderly in your home or in the person's home, it depends on how financially sound you are. If you don't have money, you will have to join the government homes but if you can afford then you can hire people." (P8)}

This assertion is in consonance with Houser et al. (2010) argument that a significant number of older disabled adults pay for their care services either from their own savings, by insurance, or through a public programmes. Arguably, from these two themes, residential facilities and non-family paid services, it can be said that research participants are well informed about what institutional care for the elderly entails.

\subsection{The Advantages of Institutional Care for the Elderly}

The study sought to identify what academics perceived as advantages and disadvantages of institutional care for the elderly in Ghana. On the question of the perceived advantages, the themes; good care provision, positive relations, refuge for underprivileged elderly (specifically from responses that described it as a residential facility) and relief for family members (specifically from responses that described it as a non-family paid service) emerged from the data.

\subsubsection{Good Care Provision}

Majority of research participants expressed faith in Institutional Care for the Elderly that in such institutions the elderly would receive the necessary care which would ensure they live longer. One research participant said;

"Well I think in such an institution the elderly will receive the necessary support that they need. That would even make them live longer." (P7)

This finding is indicative that some of the research participants perceived institutional care as a place where quality care will be provided for the elderly. This is similar to an explanation by Sander and Walden (1985) who describe institutional care as a place where people live their lives with as little physical or psychosocial discomfort, dignity and a good quality of life. 


\subsubsection{Social interactions}

Some research participants were also of the view that institutional care for the elderly would provide an opportunity for them and their peers to interact and be happy. A research participant had this to say;

"I think that there (residential facility) the elderly will have the opportunity to meet other elderly individuals like themselves and they will enjoy the company that they wouldn't get even in the home. For most of the elderly, all they want is someone to be with them and talk to." (P13)

This finding also affirms Kimondo (2012) who found out that 'Affirmative relations' or 'positive relations' are an aspect of wellbeing among elderly residents in nursing homes characterized by warm trusting relations with others.

\subsubsection{Refuge for Underprivileged Elderly}

Some research participants also had the opinion that an institutional care facility for the elderly would serve as a refuge for elderly who have been abandoned by their families or those who had no one to support them. Hence, eliminating the prospects of being destitute; this was what a research participant stated;

'In our (Ghanaian) contest it will be advantageous for those who do not have anybody to take care of them. Because there are those who are begging on the street or have no relations to support them.' (P11)

Thus, those who perceive residential care as a residential facility deem the group living as a better alternative to ensure the wellbeing of the elderly in terms of care, social interactions and social exclusion.

\subsubsection{Relief for Family Members}

In addition, some research participants, who perceive institutional care as a paid service provided by non-family members, asserted that a derivable advantage of institutional care for the elderly is that it would relieve the close relations of the elderly of the 'burden' of having to take care of their elderly. They further explained that the other relatives who work would have full concentration on their jobs with the knowledge that their parents or elderly relatives are safe. One research participant explained;

"...it leaves the children free since they know their parents are being taken care of so they can concentrate and engage in productive work. Because some people have to stop working just to take care of their old parents." (P1)

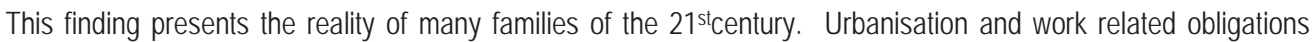
have made relatives move away from the elderly therefore the availability of a service to care for their loved ones might relief them of the guilt of neglecting their elderly relatives.

\subsection{The Disadvantages of Institutional Care for the Elderly}

Yet, there were other research participants who shared the view that introducing institutional care for the elderly in Ghana will results in; breakup in family ties, emotional discomfort, public stigmatisation and poor care provision.

\subsubsection{Breakup in Family Ties}

Research participants who expressed this concern argued that sending one's elderly relatives or parents to an institutional care facility breaks the bond between them as a family which is a cherished value. This is how one of the research participants argued;

"...socially, we lose the bonding between our parents. Personally I love being with my mum. If I had to send her to a home, it would be difficult for me. In my case, maybe l'll employ somebody to take care of her in my home...." (P11)

These opinions are indicative that there is the fear that family bonds could be broken if elderly relatives are sent to residential facilities. 


\title{
3.3.2 Emotional Discomfort
}

Some research participants held the view that sending the elderly to an institutional care facility would be discomforting for the elderly since they would have to adjust to the new environment and start 'new' relationships. A research participant who held this view stated;

'The elderly won't be happy about it. They will feel abandoned.' (P7)

Teeri et al. (2006) had a similar finding which they termed as 'lack of autonomy'. The authors explained that elderly residents in Homes felt depressed and not valued and lamented that their right to 'self-determination' had been trampled upon by their children.

\subsubsection{Public Stigmatisation}

Most people are concerned about what others say about them; this was the position of some of the research participants that society will frown upon people who would send their elderly to an institutional care facility. One research participant commented;

\begin{abstract}
"Well, it will be seen as abandoning your parents. In our cultural contest there is an adage that your parents look after you for your teeth to grow and you in turn look after them for theirs to remove. So if you send them to such an institution, it will be neglecting them. The society will think of you as a deviant". (P3)
\end{abstract}

This sentiment suggests that there is the fear of stigmatisation of derogation of duties to parents, as a result some research participants might be reluctant to seek for non-family intervention in the care of their elderly parents or relatives.

\subsubsection{Poor Care Provision}

Reports about poor care provision in orphanages across the nation has left a lot of people to lose faith in human service personnel. Against this backdrop, some research participants were of the view that an institutional care facility for the elderly set up in Ghana would suffer the same fate as orphanages with poor care provision. This was what a research participant had to say;

'Well I do not think such institutions would work here in Ghana or Africa. Given our cultural background and the way we do things. If we look at our orphanages, are they working properly? Just yesterday we heard what has been happening in the Bawjiase Orphanage (a privately owned orphanage where there was alleged abuse)' (P18)

Majority of the research participants cited 'Poor Care Provision' as a major area of concern. This is indicative that, though the elderly could receive good care in a residential care institution which is deemed as a major advantage, it was evident that some were sceptical of the kind of services that will be provided based on the operations of existing child care institutions.

\subsection{Institutional Care for the Elderly as an alternative care option}

One of the objectives of the study was to explore if academics will consider institutional care as an alternative care option for the elderly in Ghana. Emerging themes from the interview data of research participants who had the opinion that institutional care for the elderly was a relevant alternative care option were; extinction of the extended family system, financial problems and health problems.

\subsubsection{Extinction of the extended family system}

Some research participants argued that urbanisation has caused the collapse of the traditional Ghanaian societies that ensured that families catered for their elderly. One research participant explained;

"I would say it (institutional care for the elderly) is a necessary alternative because there are several elderly people who have nobody to take care of them which did not happen in our traditional societies and they are languishing in poverty so we should have such a facility to deal with cases like that." (P11) 
This sentiment is also shared by Nukunya (2003) who said that the 'we' concept of Africans are dying due to modernisation.

\subsubsection{Financial problems}

Other research participants were of the view that the local economic situation is such that the youth are unable to cater for their own personal needs left alone their elderly dependents. Therefore, they believe that a residential facility will help cater for those elderly dependents in the country who might have no financial resources largely due to improper planning and the inadequate provision of the pension schemes in the country. A research participant summed his views:

"The economic situation is so bad. Even the young who are strong are not even getting jobs. So what will happen if it goes on for a long time? So the situation is so difficult and that is what usually brings problems to our elderly. So if we develop such institutional care, it can at least get the burden off the youth" (P5)

Indeed the Ghana Statistical Service confirms high unemployment rates among the youth within the age of bracket of 15 - 44years (Ghana Statistical Service, 2012). As a result, people are unable to adequately cater for their needs and that of their elderly dependents. This therefore makes institutional care a relevant alternative due to the existing financial problems in the country.

\subsubsection{Health problems}

Some research participants were also of the opinion that such institutions (specifically residential facilities) will better address the numerous health challenges of the elderly. A research participant explained that health problems are the most challenging issues of the elderly and that they require special care in their old age which he believes institutional care facilities for the elderly can help with. He stated;

"Well for my mum for instance it is her health. She complains of one ailment after another. Just the last time she said her eyes, she couldn't see properly. I think those who have no carers will have difficulty in meeting their health needs" (P4)

One research participant said that even in cases where the family is around to support the elderly, they might require extra care services which families cannot provide. She argued;

"I can adequately support my mother financially so I don't think she will have a lot of issues. But at that age, they have a lot of health complications as well which I wouldn't be able to cater for so if there were such an institution with professionals that can cater for her health than I would consider it." (P12)

From the above, institutional care for the elderly is considered as a necessary care option for Ghana because of challenges faced by the elderly with regards to the breakdown of extended family systems, financial challenges and health problems. These issues expressed by the research participants are not different from what Becky (2005) identified; hence the findings suggest that the need for institutional care is not the preserve of more advanced countries but in countries such as Ghana, it is an option that is worth considering.

However, some research participants were of the view that having an institutional residential facility for the elderly in Ghana was irrelevant, mainly due to the abysmal performance of existing residential care institutions.

\subsubsection{Abysmal performance of care institutions}

However, there were a few research participants who rejected institutional care as an alternative care option for elderly in Ghana by citing poor care services in existing residential care institutions like orphanages. One research participant said;

"Well the already existing institutions like the orphanages and the rest are not working. So personally I think if we introduce such elderly homes, they will suffer the same fate. That's what I think personally. Some of these things I look at them with suspicion, because it's just a few people who do sacrificial work in Ghana. Because people might establish it with good intentions and later on become corrupted in a way. When the donor aids are coming then it will be going somewhere." (P5) 


\subsection{Management of Institutional Care for the Elderly in Ghana}

Another objective was to explore how institutional care facilities should be managed in Ghana. Three themes emerged from the interview data, these were Institutional care should be managed: by government, be privatised and should be a shared responsibility by government and the private sector.

\subsubsection{Managed by Government}

Research participants who held this view argued that most of the elderly are retired government employees who had worked for the most part of their lives for the development of the country. Therefore, it was incumbent on government to as it were 'pay them back' by setting up residential facilities that would cater for them in their old age. A research participant explained that it would be 'dignifying' to be in a residential home when old by stating;

"I think it's a bit dignifying to have all the elderly in a place that they see themselves in a group of their age mates after retirement." (P19)

Some research participants further explained that it was government's responsibility to cater for the elderly who had no one to take care of them and were on the streets. Adding that funding for the provision of institutional care would not be a problem for the government. This was the opinion expressed by one research participant;

"Money is not a problem, if money is an issue then it's because we don't manage our resources well. We need a benevolent dictator, a soldier man who will whip everybody into line, I'm not calling for a coup d'état, but sometimes we need such leadership. We shouldn't allow our aged to die that miserably. That's one thing that makes me sad, very old people who find it difficult to eat. But unfortunately, we don't have leaders who will think about those things." (P2)

The Ghanaian Constitution, under article 37(6b), states that the "State provide social assistance to the aged such as will enable them to maintain a decent standard of living". This therefore justifies the suggestion by research participants since there is a constitutional provision that puts the onus on the State to provide such services.

\subsubsection{Privatisation of Institutional Care}

Other research participants had the view that care provision is an essential service, either as a residential facility or nonfamily paid service. Therefore, it should be managed by private organisations which can be regulated and be held accountable for their services. It was however emphasised that such care would be expensive and not everyone could afford. One research participant stated;

"Well I do not believe we can leave everything to the government. Yes for those who worked in the government sector, they have worked most of their lives to develop our country. So for such people government should take a part of their cost or if all of it. But for others, their families can pay. But sincerely I believe it should be privatised because only then can we hold them accountable but that too there would be the issue of affordability. But it should be done well, with proper regulations and laid down policies. But let the private individuals take charge and make it privatised." (P7)

Some research participants also held the view that a residential care institution, based on the situation in similar care institutions like the orphanages, will be mismanaged. One research participant said;

'Well personally I do not trust the government. This will be established and funds allocated for it will find its way into people's pockets. Even at the orphanages where they are small children, their funds and food are being embezzled how much more the elderly. It should be established by private individuals'. (P5)

This response is not different from Choi et al. (2008) who said that elderly residents in private homes received 'better' care than their counterparts in government homes. This therefore calls for strong regulations and policy guidelines to be developed to guide the administration and conduct of care homes set up for the elderly. 


\title{
3.5.3 Shared responsibility by Government and Private Sector
}

Research participants who expressed this concern believe that best practices suggest that institutional care for the elderly should be run by government. However, in the Ghanaian context due to government's inability to fund other similar care services, individuals should be allowed to complement government's efforts. One research participant had this to say;

\begin{abstract}
"Well outside in the developed world, their government has a well-structured social welfare system unlike our place, here things like that won't work. It reflects in services like the NHIS, our transport and other services. So if we leave this for the government, we will see the same results. So probably, if people would invest into that, but if they do that too, they will want to recoup profit and only a few people can afford. Ideally, it should be government and maybe funds from international donor agencies. People could also be made to contribute" (P1)
\end{abstract}

This finding in line with what happens in the developed countries (Schulz, 2010; Wysocki et al., 2012; Harris et al., 2013). Medicaid, in the United States for instance funds LTC which receives contribution from individuals complemented by government provision (Harris et al., 2013). The Ghanaian government can therefore take a cue from this and establish a system where individuals would pay to complement government's effort with the development of institutional care structure for the elderly.

\section{Conclusion}

The provision of care for the elderly is another care service that needs policy directions in Ghana. Responses from the research participants reveal that institutional care for the elderly were perceived as a residential and non-family paid service in the provision of care for the elderly. However from this study, it appears the question of cultural values supersedes rational thinking in relation to non-family members caring for the elderly. Majority of the academics in this study acknowledged the benefits of having an institutional care for the elderly in Ghana but some argued that it will not be an option they will prefer which could be attributed to cultural implications. Hence, there is a need to rethink and engage stakeholders to make the concept more acceptable to Ghanaians. This could be done by introducing day care centres for the elderly, a centre that is likely to be perceived as more recreational, where care needs of the elderly will be attended to and they will return home at the end of the day. Also education to destigmatise institutional care for the elderly might help Ghanaians to gradually accept the concept of the provision of adequate care for the elderly if there is no family support.

Further, the question of provision of adequate care if the elderly were to be placed in a residential facility was a recurrent theme. Some of the research participants argued on the advantages of meeting the needs of the elderly; whilst others highlighted the inefficiency and ineffectiveness in practice. Those who shared their misgivings repeatedly highlighted the failure of existing residential care institutions, especially for children, in providing adequate care for the individuals placed in the care of officials. They were of the view that similar fate will befall the elderly if their care needs are to be addressed by paid personnel. Therefore, as a country there is a need to train more officials in gerontology for them to have the requisite skills to attend to the elderly before such services are introduced and to encourage privatepublic partnership to ensure efficient and effective provision of care services for the elderly.

Family ties are very important for the wellbeing of the elderly. Although, filial love cannot be regulated by social policies, the elderly need to be protected and adequately cared for; therefore Ghana needs to develop an alternative care option for the elderly who lack adequate care. This study, albeit unrepresentative of the Ghanaian population, has provided an insight into how a section of the population perceives institutional care for the elderly. Institutional care was not universally accepted neither was it rejected as alternative care option. Hence, there is the need for a national discourse which will aid in the shaping of social policies to address the care needs of elderly Ghanaians.

\section{References}

Andresen, M. \& Puggaard, L. (2008) Autonomy among physically frail older people in nursing home settings: a study protocol for an intervention study. BMC Geriatrics, 8:32 doi:10.1186/1471-2318-8-32

Andresen, M., Runge, U., Hoff, M., \& Puggaard, L. (2009). Perceived Autonomy and Activity Choices among Physically Disabled Older People in Nursing Home settings: A Randomized Trial, Journal of Aging and Health, 21(8):1133 - 1158, doi: 10.1177/0898264 30934819.

Atchley, R. C. \& Barush, A. S. (2004). Social Forces \& Aging: An Introduction to Social Gerontology. Belmont, CA: Wadsworth/Thomson Learning.

Beauchamp, T. L., \& Childress, J. F. (2009). Principles of biomedical ethics (6th ed., pp. 38-39). New York, NY: Oxford University Press. 
Becky, C. (2005). The Dilemma of Ageing in Ghana. Retrieved Nov 13, 2014 from http://ghanaweb.com/GhanaHomePage/health/ artikel.php?ID=95209.

Berg, B. L. (2001). Qualitative Research Methods for the Social Sciences. (4th ed.). London: Allyn \& Bacon.

Bruce, C. (2007). Questions arising about emergence, data collection, and its interaction with analysis in a grounded theory study. International Journal of Qualitative Methods, 6(1): 51-68.

Choi, G. N., Ransom, S., \& Wyllie, J. R. (2008). Depression in older home residents: The influence of nursing home environmental stressors, coping, and acceptance of group and individual therapy. Aging and Mental Health 12(5), 536-547.

Creswell, J. (2013). Qualitative inquiry and research design: choosing among five approaches. London: Sage Publications.

Francis, J., Johnston, M., Robertson, C., Glidewell, L., Entwistle, V., Eccles, M. \& Grimshaw, J. (2010). What is an adequate sample size? Operationalising data saturation for theory-based interview studies. Psychology \& Health, 25(10): 1229-1245.

Ghana Statistical Service (2012). 2010 Population \& Housing Census: Summary Report of Final Results. Accra: Ghana Statistical Service.

Ghana Statistical Service (2013). 2010 Population \& Housing Census: The Elderly in Ghana. Accra: GoG/UN.

Gorman, M. \& Petersen, T. (1999). Violence against older people and its health consequences: experience from Africa and Asia. London: HelpAge International.

Guest, G., Bunce, A. \& Johnson, L. (2006). How many interviews are enough? An experiment with data saturation and variability. Field Methods, 18(1): 59-82.

Haber, C. (1977). The Old Folks at Home: The Development of Institutionalized Care for the Aged in Nineteenth-Century Philadelphia. The Pennsylvania Magazine of History and Biography, 101(2) 240-257.

Harris, K. L., Sengupta, M., Park, L. E. \& Valverde, R. (2013). Long-term care services in the United States: 2013 Overview. New York: Centers for Disease Control and Prevention.

Houser, A., Gibson, M. J. \& Redfoot, D. L. (2010). Trends in Family Caregiving and Paid Home Care for Older People with Disabilities in the Community: Data from the National Long-Term Care Survey. AARP.

Kimondo, J. W. (2012). Benefits and Challenges encountered by Elderly Living in Nursing Homes: Human Ageing and Elderly Services. Helsinki: Arcada University Press.

Little, William (2013). Introduction to Sociiology. Retrieved on July 27, 2015 from http://opentextbc.ca/introductiontosociology/.

Marvasti, A. B. (2004). Qualitative Research in Sociology: An Introduction. London: Sage Publications.

Murphy, K., Shea, O. E., \& Cooney, A. (2006).Quality of life for older people living in long-stay settings in Ireland. Journal of Clinical Nursing, 76, 93-105.

Nukunya, G. (2003). Tradition and Change in Ghana: An Introduction to Sociology. Accra: Universities Press.

O'Loughlin, A. \& Duggan, J. (1998). Abuse, neglect and mistreatment of older people: an exploratory study. Dublin: National Council on Ageing and Older People, (Report No. 52).

Pillay, N. K. \& Maharaj, P. (2013). Population Ageing in Africa. New York: Springer Science Business Media.

Sander, R. \& Walden, P. (1985). So much to learn: long-stay wards. Nursing Times, 80(322): 50-51.

Schulz, E. (2010). The Long-Term Care System for the Elderly in Germany. Berlin: Ancien Publications.

Scott, P. A., Valimaki, M., Leino-Kilpi, H., Dassen, T. Gasull, M., Lenonidou, C. Arndt, M. (2003) Autonomy, privacy and informed consent 3: elderly care perspective. British Journal of Nursing13-26;12(3):158-68.

Stevenson, Karen (1994) History of Long Term Care. Retrieved on July 27, 2015 from http://www.elderweb.com/book/export/html/2806/

Teeri, S., Leino-Kilpi, H., \& Välimäki, M. (2006). Long-Term nursing care of Elderly People: Identifying Ethically Problematic Experiences Among Patients, Relatives And Nurses In Finland. Nursing Ethics, 13(2), 116 - 129.

Tibutt, L. R. (1983). An evaluation of Institutional Care of the Aged in South Africa. Retrieved October 13, 2014 from http://mww.ncbi.nlm. nih.gov/m/pubmed/6879.

UN (2002). Political Declaration and Madrid International Plan of Action on Ageing. New York: United Nations.

United Nations Population Fund \& HelpAge International. (2012). Ageing in the twenty-first century: A celebration and a challenge. Retrieved February 16, 2015 from http://www.helpage.org/download/50af6e052ed68.

World Health Organisation (2006).Elder Abuse and Alcohol. Geneva: World Health Organization.

World Health Organisation (2008).The World Health Report 2008: Primary Health Care now more than ever. Geneva: World Health Organization.

Wysocki, A., Butler, M., Kane, R.L., Kane, R. A., Shippee, T. \& Sainfort, F. (2012). Long-Term Care for Older Adults: A Review of Home and Community-Based Services versus Institutional Care. Minnesota: Sage Publications. Comparative Effectiveness Review No. 81. AHRQ Publication No.12(13)-EHC134-EF. Rockville, MD: Agency for Healthcare Research and Quality. www.effectivehealth care.ahrq.gov/reports/final.cfm. 